\title{
Potential source areas for Lower Volga loess: provenance analysis using detrital zircon U-Pb ages
}

\author{
Chiara Költringer $^{1, *}$, Thomas Stevens ${ }^{1}$, and Redzhep Kurbanov ${ }^{2,3}$ \\ ${ }^{1}$ Uppsala University, Dept. of Earth Science, 75236 Villavägen 16, Sweden \\ ${ }^{2}$ MSU, Lomonosov Moscow State University, Faculty of Geography, M.V., Leninskie Gori, 1, Moscow 119992, Russia \\ ${ }^{3}$ RAS, Laboratory of Evolutionary Geography, Institute of Geography, Staromonetny, 29, Moscow 119017, Russia
}

\begin{abstract}
Knowledge about origin and transport of aeolian mineral dust in the past and modern times plays an important role in the understanding of climate. Atmospheric circulation patterns and dust dynamics can be revealed by tracing back the provenance of airborne material. The source of loess deposits in the Lower Volga region of Russia is not known, yet represents a key location for Eurasian climate history reconstruction. The problem is addressed using $\mathrm{U}-\mathrm{Pb}$ dating of detrital zircons from the loess deposits and potential source sediments such as East European Plain, Crimea, Caucasus, Volga, Caspian Sea and Central Asian desert sediments. Identifying the actual source of Lower Volga loess will help to understand past dust transport pathways and climate evolution in the region and its implications for regional and global climate.
\end{abstract}

\section{Introduction}

Understanding of source and sink locations of atmospheric mineral dust is essential for many climate related questions. Airborne material can be transported over distances of thousands of kilometres until its location of deposition. Tracing back the origin of windblown material helps to unravel atmospheric circulation and dust dynamics over a wide area. The understanding of aeolian dust transport and of transport processes from source to sink provides insight into globally relevant questions such as climate change and its evolution in certain parts of the world. However, this is not only of relevance in the present day. Loess deposits represent excellent records of past aeolian mineral dust and serve as informative climate archives, allowing climate reconstructions for the time frame of their accumulation. The variation of dust input to sink regions is strongly controlled by climate. Representing deposited windblown material, loess deposits and the knowledge of its provenance provides important insights into past atmospheric conditions, wind patterns and dust dynamics.

Loess deposits along the Lower Volga River in the Caspian Sea region of Russia are located right in the middle of the vast mid latitude Eurasian loess belt, which stretches from East Europe to East Asia. While East European as well as East Asian loess deposits are intensively studied, loess of the Lower Volga region has not gained much research interest until recently. Accordingly, the source and provenance of Lower Volga loess remains unconstrained, making it a missing link for developing full understanding of aeolian dust and
Eurasian continental atmospheric circulation history. Hence, resolving the source and transport of this Volga loess is crucial for understanding climate and dust evolution in Eurasia.

Here we use $\mathrm{U}-\mathrm{Pb}$ dating of detrital zircons from loess and potential source material to address the question of its provenance. Zircon U-Pb dating is a successfully applied tool for provenance analyses in loess research [1-5]. It has been found particularly powerful in deciphering multiple sources, which may be ambiguous from bulk sample geochemical data [2].

\section{Material and Methods}

The study focuses on loess material from three sections along the lower branch of the Volga River and its multichannel system: Srednaya Akhtuba, Leninsk and Raigorod (Fig. 1). Bulk loess samples of 1-2 kilos were taken from different stratigraphic depths at all three sites. Modern sediments in potential source areas were sampled as well. Zircons were separated from the bulk material following traditional methods of sieving, washing, heavy liquid density separation and Frantz magnetic separation. Samples were processed in a way so that all zircons would remain in the final heavy mineral fraction. This separated zircon fraction was mounted in epoxy and prepared for Laser-Ablation Multicollector ICP Mass Spectrometry (LA-MCICPMS) analysis together with primary standards at the University of Arizona LaserChron Center. Backscatter Electron Images of the mounts were created via Scanning Electron Microscopy beforehand. The U-Pb

* Corresponding author: chiara.koltringer@geo.uu.se 
age datasets were collected in a high $\mathrm{n}$ attempt by measuring at least 300 grains per sample. Measured zircons were chosen on a random basis in order to avoid any kind of bias and to cover all present grain sizes and shapes. Data reduction and analyses was performed using the in-house routine of the Arizona LaserChron Center (written by John Hartman, University of Arizona).

\section{Potential source areas}

The choice of potential source samples was based on considerations of likely paleoclimate conditions [6] as well as on overall accepted requirements an area needs to bring for being able to act as source of aeolian mineral dust. Only areas with sufficient supply of material are considered to be a potential source for several meter thick loess sequences. In the same manner the material needs to be available for wind transport. Thus the possibility of deflating dust to the atmosphere must be a given. This requires intensive erosion and accumulation in wind exposed locations. Furthermore, the distance and location of the source relative to the sink is also important to consider. Topographic obstacles such as orogens are considered to hinder aeolian transport. Moraine and loess material from the Eastern European/ Russian plain (EEP) supposedly made its way to Southern Russia via multi-step transport being blown or washed out from the Scandinavian ice shield glacier forefield, partly transported by rivers, potentially the Don River, and eventually wind transported from floodplains on its last stage of transport. Also Volga River floodplains could act as source in similar manner (VRS). Eroded bedrock material from the Caucasian (Cauc) and Crimea (Crim) are considered due to their relative vicinity and high erosion rates in the mountains. Respective source samples were collected from mountain alluviums and local diluviums. A highly possible near-source for Lower Volga loess are the vast marine terraces of the Caspian Sea (CSTS) distributed over the Volga lowland and along the Caspian Sea coast of Kazakhstan and Turkmenistan. Furthermore, the possibility of Central Asian deserts representing a potential source for Lower Volga loess deposits is discussed. As part of the vast desert belt, reaching from the Sahara, over Middle Eastern to East Asian deserts, Central Asian deserts represent a main source of atmospheric dust in the area. Its possible transportation over wide distances qualifies Central Asian deserts as another potential source area for loess of the Lower Volga Region in Russia. Samples were taken from the Karakum desert in Turkmenistan. Figure 1 shows the considered areas of provenance for Lower Volga loess.

\section{Results and Discussion}

${ }^{206} \mathrm{~Pb} /{ }^{238} \mathrm{U}$ ages for zircons younger than $900 \mathrm{Ma}$ and ${ }^{206} \mathrm{~Pb} /{ }^{207} \mathrm{~Pb}$ ages for older grains are used as best age for all zircon aliquots of the samples. The first results show a very similar $\mathrm{U}-\mathrm{Pb}$ age distribution for Volga loess at different stratigraphic levels indicating no significant

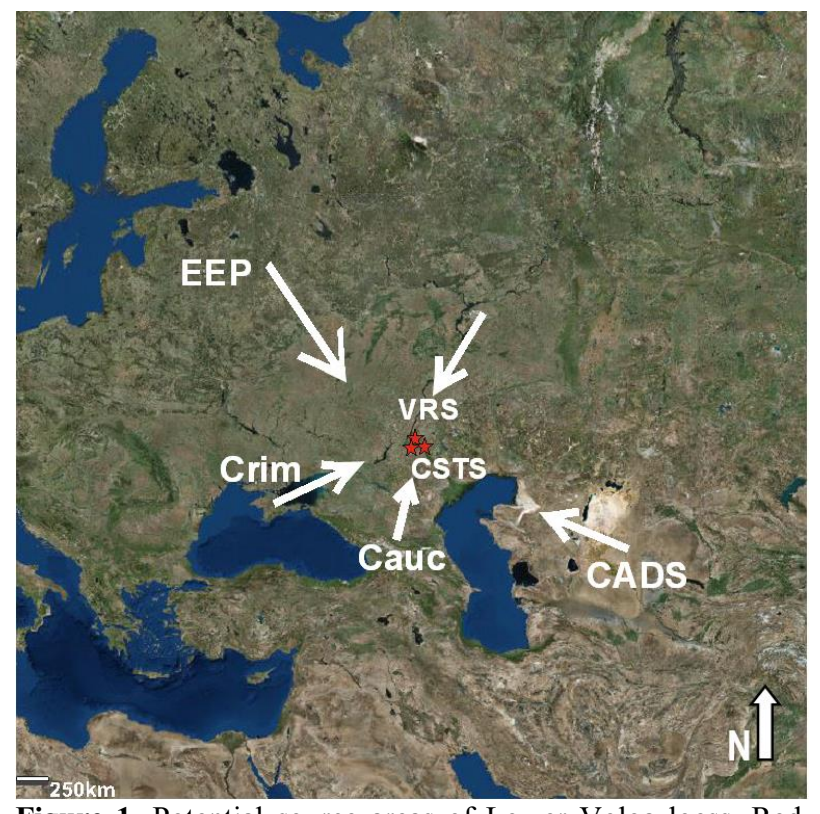

Figure 1. Potential source areas of Lower Volga loess. Red stars mark the location of sampled Lower Volga loess sites, arrows indicate the origin and direction of transport of potential source material abbreviated as followed: EEP (East European Plain sediments), VRS (Volga River Sediments), CSTS (Caspian Sea Terrace Sediments), CADS (Central Asian Desert Sediments), Cauc (Caucasus sediments), Crim (Crimean sediments) (basemap by esri [7]).

change of source during the times of accumulation. The resultant age spectra of the loess show five principal age components. One distinct age peak is at around $360 \mathrm{Ma}$, another set of age fractions can be identified between $1000 \mathrm{Ma}$ and $2000 \mathrm{Ma}$ with peaks at around $1070 \mathrm{Ma}$ to $1100 \mathrm{Ma}$ and $1500 \mathrm{Ma}$ to $1900 \mathrm{Ma}$, two minor peaks at $2450 \mathrm{Ma}$ and $2700 \mathrm{Ma}$ identify older zircon age components. $\mathrm{U}-\mathrm{Pb}$ zircon age distributions of Volga river sediments show close similarities to Volga loess, suggesting a relationship between river and aeolian sediment material origin. Source material from the Caucasus by contrast shows different age peaks. It exhibits young ages that define a peak at $250 \mathrm{Ma}$, while the age fractions between $1000 \mathrm{Ma}$ and $2000 \mathrm{Ma}$ show lower abundance and different distribution. The Caucasus region is therefore excluded as major source area for Volga loess based on these detrital zircon data.

\section{Conclusion and Outlook}

In this study the comparison of zircon $\mathrm{U}-\mathrm{Pb}$ age spectra of Volga loess and the potential source material will be used to rule out and narrow down the considered source sediments, and if possible to identify the provenance, of Lower Volga loess. The first preliminary and further results of other potential source regions will be discussed. Furthermore, tracing back the origin of loess in the Lower Volga region is intended to build the base for reconstructing mechanisms and steps of its transport. Thus, the implications for past aeolian dust transport in the region will be addressed. 


\section{References}

1. J.N Aleinikoff., D.R. Muhs, E.A. III Bettis, W.C. Johnson C.M.R. Fanning, Geol. Soc. Am. Bull., 120, 1362-1377 (2008)

2. T. Stevens, C. Palk, A. Carter, H. Lu, P. D. Clift, Geol. Soc. Am. Bull. 122 (7-8), 1331-1344 (2010)

3. A. Pullen, P. Kapp, A.T. McCallister, H. Chang, G.E. Gehrels, C.N. Garzione, R.V. Heermance, L. Ding, Geology, 39, 1031-1034 (2011)

4. G. Újvári, A. Varga, F.C. Ramos, J. Kovács, T. Németh, T. Stevens, CHEM GEOL, 304-305, 83-96 (2012)

5. G. Xiao, K. Zong, G. Li, Z. Hu, G. Dupont-Nivet, S. Peng, K. Zhang, Geophys. Res. Lett., 39, L20715 (2012)

6. T. Yanina, Quat. Int., 345, 88-99 (2014)

7. Esri. "Imagery" [basemap], 1:25000000 "World Imagery Map", January 10, 2019. http://www.arcgis.com/home/webmap/viewer.html? useExisting=1 (January 23, 2019) 